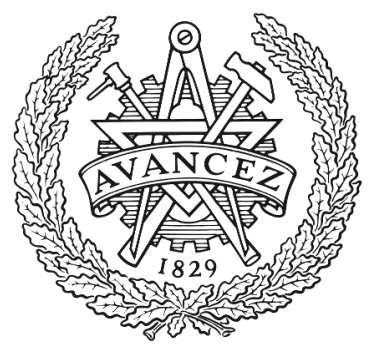

CHALMERS

UNIVERSITY OF TECHNOLOGY

\title{
An energy and resource efficient alkaline flocculation and sedimentation process for harvesting of Chromochloris zofingiensis biomass
}

Downloaded from: https://research.chalmers.se, 2023-04-26 08:47 UTC

Citation for the original published paper (version of record):

Mayers, J., Landels, A., Allen, M. et al (2020). An energy and resource efficient alkaline flocculation and sedimentation process for harvesting of Chromochloris zofingiensis biomass. Bioresource Technology Reports, 9. http://dx.doi.org/10.1016/j.biteb.2019.100358

N.B. When citing this work, cite the original published paper. 


\title{
An energy and resource efficient alkaline flocculation and sedimentation process for harvesting of Chromochloris zofingiensis biomass
}

\author{
Joshua J. Mayers ${ }^{\mathrm{a}}$, Andrew R. Landels ${ }^{\mathrm{b}, \mathrm{c}}$, Michael J. Allen ${ }^{\mathrm{b}, \mathrm{d}}$, Eva Albers ${ }^{\mathrm{a}, *}$ \\ ${ }^{\text {a }}$ Chalmers University of Technology, Department of Biology and Biological Engineering, Division of Industrial Biotechnology, SE-412 96 Göteborg, Sweden \\ ${ }^{\mathrm{b}}$ Plymouth Marine Laboratory, The Hoe, Plymouth PL1 3DH, United Kingdom \\ ${ }^{\mathrm{c}}$ Rothamsted Research, Harpenden AL5 2JQ, United Kingdom \\ ${ }^{\mathrm{d}}$ College of Life and Environmental Sciences, University of Exeter, Exeter EX4 4QD, United Kingdom
}

A R T I C L E IN F O

\section{Keywords:}

Microalgae

Harvesting

Sedimentation

Flocculation

Life-cycle assessment

\begin{abstract}
A B S T R A C T
Harvesting microalgal cultures is often energetically intensive and costly. To improve efficiencies, a two-step harvesting method utilising alkaline flocculation and sedimentation to pre-concentrate cultures can be used prior to centrifugation. When applied to the microalga Chromochloris zofingiensis, high rates of sedimentation ( $>90 \%)$ were found at low concentrations of base $(<10 \mathrm{mM})$, with the addition of magnesium to the media (via $\mathrm{NaOH} /$ $\mathrm{MgSO}_{4}$ or $\mathrm{Ca}(\mathrm{OH})_{2} / \mathrm{Mg}(\mathrm{OH})_{2}$ ) to form $\mathrm{Mg}(\mathrm{OH})_{2}$. The process was scaled to $180 \mathrm{~L}$, where sedimentation was as efficient as that achieved at bench scale. Characterisation of the harvested biomass showed comparable composition (following neutralisation of $\mathrm{pH}$ ) to biomass recovered solely by centrifugation. The alternative two-step processes were assessed for environmental impacts and cost, which indicated that a two-step harvesting generally performs better than centrifugation alone, but that the locally available electricity source is a critical parameter for optimal solution.
\end{abstract}

\section{Introduction}

Significant advances in microalgal biotechnology have been achieved and e.g. feed production may be close to realisation, yet for large-scale bioenergy production substantial improvements are still necessary (Ruiz et al., 2016; Taelman et al., 2015). Harvesting (dewatering) of biomass from the culture medium is considered one of the costlier aspects of microalgal processing as a consequence of very dilute cultures ( $<0.3 \%$ dry weight, DW) and handling of large liquid volumes (Gerardo et al., 2015; Ruiz et al., 2016; Vandamme et al., 2013; Weschler et al., 2014). Further challenges are the small sizes of cells $(<50 \mu \mathrm{m}$ ), unfavourable buoyancies (depending on species and biochemical composition) (Hathwaik et al., 2015; Muto et al., 2017), and the negative surface charges of most species which result in electrostatic repulsion and cells remaining suspended (Lama et al., 2016). Thus, effective harvesting needs to be optimised for both algal species and product configuration to minimise energy expenditure.

Centrifugation is the most widely used harvesting technique at commercial scale due to its simplicity, high biomass recovery efficiency and the high solid concentrations achieved; however, the operation of this equipment is energetically costly and the capital investment significant (Dassey and Theegala, 2013; Weschler et al., 2014), e.g. up to
$10 \mathrm{kWh} \mathrm{m}^{-3}$ at demonstration scale (Beal et al., 2015; Huntley et al., 2015). When high biomass containing pastes are required, techniques that can decrease the volume of liquid sent to centrifugation are imperative to enable efficient harvesting. To this end, flocculation, flotation, membrane filtration and other emerging technologies have all been considered as useful options for the pre-concentrating step (Gerardo et al., 2015).

Inducing flocculation of microalgal cells into larger aggregates using chemicals, followed by gravity sedimentation, is considered to be feasible for large scale applications due to its relatively low cost and scalability (Vandamme et al., 2013). The mechanism of flocculation depends on the chemicals used, but involves three principles of forming aggregates (solely or in combination): neutralisation of the negative cell surface; linking/bridging of cells by particular molecules; and larger aggregate/floc formation (often hydroxides, carbonates or phosphates) and cellular entrapment i.e. 'sweeping' (Branyikova et al., 2018). Investigated chemical flocculants include metal salts (alum or ferric chlorides/sulphates), biopolymers (cationic starch or chitosan) and bases. In alkaline flocculation, $\mathrm{pH}$ is increased by adding base, often $\mathrm{NaOH}$ and occasionally $\mathrm{Ca}(\mathrm{OH})_{2}$, and is considered to cause chemical bridges between cells and aggregate formation, leading to sweeping. Drawbacks of using metal salts and biopolymers are that the harvested

\footnotetext{
* Corresponding author.

E-mail address: albers@chalmers.se (E. Albers).
} 
biomass is contaminated, which can limit the possibilities of its use because of toxicity and regulatory restrictions. Additionally, the presence of flocculants can influence downstream processing and they are often associated with higher incurred costs compared to bases (Branyikova et al., 2018; Wan et al., 2015).

The use of alkaline flocculation, therefore, offers a simple and relatively effective harvesting method, which benefits from the reversible removal of flocculant by neutralisation of the recovered biomass (Garcia-Perez et al., 2014; Vandamme et al., 2015; Zhang et al., 2016). Flocculation efficiencies over $90 \%$ are achievable by increasing $\mathrm{pH}$ to over 9.5. Suggested flocculation mechanisms by increasing $\mathrm{pH}$ vary across different studies of Chlorella strains (microalgae widely regarded as suitable for large scale biomass production due to their robust growth characteristics), e.g. associated with precipitation of $\mathrm{Mg}(\mathrm{OH})_{2}$ (Castrillo et al., 2013; Vandamme et al., 2015), or of ferric hydroxides (Yang et al., 2016). $\mathrm{Ca}^{2+}$, carbonates and phosphates have also been implicated as having roles in sedimentation of algal cultures (Brady et al., 2014; Smith and Davis, 2012). The complexities associated with high nutrient media compositions, diverse algal physiologies, environmental conditions, material availability, local infrastructures and even variations in the $\mathrm{pH}$ during cultivation contribute to the variety of mechanisms proposed and reported in the literature.

The aim of this study was to assess alkaline flocculation for 'clean' harvest of the carotenoid producing Chromochloris zofingiensis (formerly Chlorella zofingiensis). Magnesium was used in the flocculation to enhance sedimentation and biomass recovery in bench scale experiments, prior to $180 \mathrm{~L}$ pilot scale trials. The potential mechanism of flocculation and its impact on biomass quality was assessed. Based on the empirical data, a process model was developed to assess the life-cycle impacts and cost of a two-step harvesting processes (flocculation/sedimentation followed by centrifugation) versus just centrifugation and to identify opportunities for further improvements. To our knowledge, this is the first time experimental data from different scales are combined and assessed by life cycle analysis.

\section{Materials and methods}

\subsection{Strains, stock maintenance and media}

Chromochloris zofingiensis (SAG 211/14, axenic strain) was obtained from the SAG Culture Collection of Algae (Gottingen, Germany) and transferred to agar plates and later to liquid cultures with Bold's Basal Medium 3N + V (BBM, hereafter) (Andersen, 2005), which was used in all experiments. Master cultures of the strain were maintained at $16{ }^{\circ} \mathrm{C}$ and sub-cultured every 4-5 weeks. Upon scaling up, cultures were subcultured into $25 \mathrm{~mL}$ and then $75 \mathrm{~mL}$ tissue culture flasks with hydrophobic coating and sterile $0.2 \mu \mathrm{m}$ air filter vented caps (Sarstedt AG \& Co, Germany), and maintained as described below. The base of the media was $18.2 \mathrm{M} \Omega$ deionised water autoclaved $\left(20 \mathrm{~min}, 121^{\circ} \mathrm{C}\right)$ prior to addition of salts and then adjusted to $\mathrm{pH} 7.0$ using $1 \mathrm{M} \mathrm{NaOH}$.

\subsection{Cultivation}

\subsubsection{Bench-scale experiments}

Production of biomass for use in bench-scale flocculation and sedimentation experiments was done using $1 \mathrm{~L}$ bottles as described previously (Mayers et al., 2018). Cultures were sub-cultured on a weekly basis to maintain rapid growth. Biomass concentration was determined using a standard curve between optical density at $750 \mathrm{~nm}\left(\mathrm{OD}_{750}\right)$ and biomass dry weight concentration (DW, $\mathrm{g} \mathrm{L}^{-1}$ ) based on twelve separate samples from different batch cultivations representing different physiological states (DW $=0.7895 \mathrm{OD}_{750}+0.0026, r^{2}=0.999$ ). Optical density was measured in 96-well plates (Sarstedt) using a plate reader (FLUOstar Omega, BMG Labtech $\mathrm{GmbH}$ ). Dry weight was determined by filtering a known volume of culture onto pre-combusted $47 \mathrm{~mm}$ GF/C Whatman glass microfiber filters (in triplicate). Filters were washed with double the volume of $0.5 \mathrm{M}$ ammonium bicarbonate to remove salts, dried for at least $24 \mathrm{~h}$ at $80{ }^{\circ} \mathrm{C}$, before cooling to room temperature in a desiccator (Zhu and Lee, 1997).

\subsubsection{Pilot scale cultivation}

C. zofingiensis was cultivated at $550 \mathrm{~L}$ scale in a horizontally stacked tubular bioreactor (Hamilton et al., 2015). Briefly, the photobioreactor (constructed by Bouygues Energies and Services, Manchester, UK) consisted of an array of polycarbonate $50 \mathrm{~mm}$ diameter tubes (36 tubes in total, in a 6 tube manifold formation) serving as the photostage, with stainless steel (316S) pipework to a holding tank allowing continuous circulation via a centrifugal pump (at $30 \mathrm{~m}^{3} \mathrm{~h}^{-1}$ ). The holding tank (200 L working volume) was continually sparged with air to aid oxygen removal $\left(\sim 10 \mathrm{~L} \mathrm{~min}^{-1}\right)$, while $\mathrm{CO}_{2}$ delivery was controlled through a $\mathrm{pH}$ stat system set to $\mathrm{pH}$ 7.0. Culture monitoring was performed via a Profilux 3 interface and included oxygen saturation, $\mathrm{pH}$, conductivity and temperature measurement. The medium used was standard BBM with sodium nitrate replaced by ammonium nitrate at corresponding nitrogen concentrations. The base for the media was tap water collected from the municipal supply in Plymouth, UK, which was sterilised by passing through a UV filter prior to addition of sterile nutrient stocks. The culture was illuminated using Heliospectra LX602G LED panels at approx. $200 \mu \mathrm{mol}$ photons $\mathrm{m}^{-2} \mathrm{~s}^{-1}$ ) at a $18: 6 \mathrm{~h}$ light:dark regime (no sinusoidal pattern). Culture temperature was maintained at $23{ }^{\circ} \mathrm{C}$. The culture optical density was measured daily and converted to DW equivalent using the determined standard curve (Section 2.2.1).

\subsection{Experimental plan and design of flocculation/sedimentation experiments}

Flocculation experiments were performed at different biomass concentrations to reflect those obtained by cultures grown in photobioreactors; approx. 0.5, 1.0, $1.5 \mathrm{~g} \mathrm{DW} \mathrm{L}^{-1}$. Cultures were harvested in linear growth phase by centrifugation $(12,000 \times g, 10 \mathrm{~min}$; Beckman Avanti J26-S, JA-20 rotor), washed in BBM lacking Mg, centrifuged, and re-suspended to the desired concentration in fresh BBM lacking $\mathrm{Mg}$, thereby removing any algogenic organic matter.

To identify the optimal material inputs for flocculation, a design of experiment approach was taken utilising a response surface methodology in the software package MODDE Pro (v11. MKS Umetrics AB). For each biomass concentration, a D-optimal design matrix utilising a quadratic model was used, with $\mathrm{NaOH}(4,6$ and $8 \mathrm{mM})$ and $\mathrm{MgSO}_{4}(6,8$ and $10 \mathrm{mM}$ ) with 2 replicates and 4 central point repeats resulting in 23 experimental runs, including 2 additional controls with no base addition or $\mathrm{Mg}^{2+}$ addition. Suitable concentration ranges of $\mathrm{NaOH}$ and $\mathrm{MgSO}_{4}$ were determined in preliminary experiments with greater ranges. Three bench scale trials were performed, one for each biomass concentration, which were performed on different actively growing cultures. These data informed trials done at pilot scale.

$\mathrm{Ca}(\mathrm{OH})_{2}$ and $\mathrm{Mg}(\mathrm{OH})_{2}$ were also examined as possible flocculants at bench scale using a design of experiment approach to investigate possible reductions in cost and impact of material inputs. Models were fitted with multiple linear regression for the tested parameters (e.g. $\mathrm{Mg}$, base or dry weight concentration) and flocculation efficiency. The flocculation efficiency data were logistically transformed before used in the model to be constrained between 0 and 100 , according to "Flocculation efficiency" $=\log _{10}(y-0) /(100-y)$. Model validity was examined by ANOVA analysis of the regression model, from which nonsignificant terms (alpha value $=0.01$ ) were removed.

\subsection{Flocculation and sedimentation}

\subsubsection{Bench-scale}

For small scale flocculation, $35 \mathrm{~mL}$ of culture was decanted into $50 \mathrm{~mL}$ Falcon centrifuge tubes. The $\mathrm{pH}$ was increased by addition of $0.5 \mathrm{M} \mathrm{NaOH}$ or $0.1 \mathrm{M} \mathrm{Ca}(\mathrm{OH})_{2}$. Control experiments with no additional 
base or $\mathrm{Mg}$ were also conducted. The $\mathrm{pH}$ of samples was measured after addition of base. Tubes were mixed on an orbital shaker first at $500 \mathrm{rpm}$ for $10 \mathrm{~min}$, then $250 \mathrm{rpm}$ for $20 \mathrm{~min}$, before leaving for $1 \mathrm{~h}$ for sedimentation without agitation. Samples were taken after the addition of base $\left(X_{0}\right)$ and after sedimentation $\left(X_{1}\right)$ from the middle of the clarified zone. Absorbance measurements were blanked against additional samples collected at $t_{0}$ that were centrifuged at $15,000 \times g$ for $10 \mathrm{~min}$ (Eppendorf $5417 \mathrm{C} / \mathrm{R}$ ). The flocculation efficiency was calculated as "Flocculation efficiency" $=\left(\left(X_{O}-X_{1}\right) / t_{0}\right) \times 100$. The concentration factor was determined by transferring $5 \mathrm{~mL}\left(\mathrm{~V}_{0}\right)$ of each sample to a $5 \mathrm{~mL}$ measuring cylinder with $0.1 \mathrm{~mL}$ graduation and allowing to sediment for $1 \mathrm{~h}$ before determining the sediment volume $\left(\mathrm{V}_{\mathrm{s}}\right)$. Volumes were rounded up to the nearest $0.1 \mathrm{~mL}$. The concentration factor was calculated as "Concentration Factor" $=\mathrm{V}_{0} / \mathrm{V}_{\mathrm{s}}$.

Settling velocities were calculated by using $1 \mathrm{~L}$ sedimentation cones with $1 \mathrm{~mL}$ graduations from 0 to $20 \mathrm{~mL}$ and $2 \mathrm{~mL}$ graduation from 20 to $60 \mathrm{~mL}$. A $250 \mathrm{~mL}$ volume of culture was mixed with the designated concentration of $\mathrm{Mg}$ and base, shaken as for those experiments described above. The sample was then decanted to the sedimentation cone and the $\mathrm{OD}$ at a depth equal to the $60 \mathrm{~mL}$ mark $(13.5 \mathrm{~cm}$ from the bottom of $23 \mathrm{~cm}$ deep sample) assessed at designated time points. The rate of sedimentation was then determined using reported calculations (Wang and Belovich, 2010). The sediment (flocculated cells) and supernatant of flocculation samples for these trials were separated via pipetting into separate tubes. Both fractions were titrated with $0.5 \mathrm{M}$ $\mathrm{H}_{3} \mathrm{PO}_{4}$ to $\mathrm{pH} 7.0$ to determine the acid requirement of neutralisation. This was repeated for cultures $\left(1 \mathrm{~g} \mathrm{DW} \mathrm{L}^{-1}\right)$ flocculated with $\mathrm{NaOH}$ using $\mathrm{HCl}$ as the acid.

\subsubsection{Pilot-scale trials}

To assess the scalability of this approach, flocculation and sedimentation trials were performed at $180 \mathrm{~L}$ scale in an upright settling tank ( $60^{\circ}$ incline, $\sim 40 \mathrm{~L}$ inverted cone volume) with a total volume of 200 L. Culture was pumped directly from the bioreactor to the tank with $\mathrm{NaOH}$ and $\mathrm{MgSO}_{4}$ immediately added (5 $\mathrm{M}$ and $4 \mathrm{M}$ stocks, respectively). The culture was then mixed using a vertical impeller mixer at $300 \mathrm{rpm}$ for $15 \mathrm{~min}$. Samples were taken from approximately $2 / 3$ of the depth of the tank after mixing and again after $1 \mathrm{~h}$. Biomass was collected from the sample valve at the bottom of the tank and the volume of the sediment recorded. For one of these two trials (both performed on the same day within $2 \mathrm{~h}$ of each other), the biomass was centrifuged without neutralising the sediment, while the second was neutralised using $2.5 \mathrm{M} \mathrm{HCl}$ to a $\mathrm{pH}$ of 7.0 before centrifugation, resulting in two types of harvested biomass. Samples were taken for analysis from the two harvested biomasses, as well as biomass directly from the photobioreactor (recovered by centrifugation). Flocculation efficiency was measured in the same manner as described (Section 2.4.1).

\subsection{Analytical techniques}

\subsubsection{Fourier-Transform Infrared Spectroscopy}

Briefly, freeze-dried microalgal biomass, $\mathrm{Mg}(\mathrm{OH})_{2}$ and $\mathrm{Ca}(\mathrm{OH})_{2}$ were measured on a PerkinElmer Spectrum Frontier instrument equipped with a diamond crystal iATR reflectance cell (Pike GladiATR) with a DTGS detector scanning wavenumbers $4000-700 \mathrm{~cm}^{-1}$ at a resolution of $2 \mathrm{~cm}^{-1}$. Three replicates (each with an average of 16 scans) for each sample were taken and the results averaged. Background correction scans of ambient air were made prior to each sample scan. Scans were recorded using the PerkinElmer spectroscopic software Spectrum (version 10. PerkinElmer, Germany).

\subsubsection{Biochemical determination}

Biochemical composition was determined for the two types of harvested biomass and original biomass generated during the pilot scale trial. Protein and carbohydrates were measured as described (Mayers et al., 2018). Ash was determined by combusting a known volume of freeze-dried biomass at $550{ }^{\circ} \mathrm{C}$ for $3 \mathrm{~h}$ in pre-weighed and pre-combusted crucibles. Total chlorophyll and carotenoids were extracted in DMSO at $60{ }^{\circ} \mathrm{C}$, and absorbances were converted to concentrations (Wellburn, 1994). Determination of C, N, H and S was done using a Vario MICRO Cube elemental analyser (Elementar) using the manufacturers recommendations.

\subsubsection{Inductively-Coupled Plasma Sector-Field Mass Spectrometry (ICP-} MS)

ICP-MS analysis was performed to identify the major salts in the sedimented algae and to ascertain if neutralisation of the biomass sediment removed these components. Freeze-dried microalgae were analysed by ALS Scandinavia AB (accredited by the Swedish National Accreditation body and are ISO 17025 compliant). Briefly, duplicates for the samples were digested in $3 \mathrm{M} \mathrm{HNO}_{3}$ and filtered to $0.2 \mu \mathrm{m}$ before analysis.

\subsection{Cost and life-cycle impact assessment}

Using the empirical flocculation data generated, process models were developed for the different two-step harvesting techniques, for which the following steps were considered: 1) flocculation and sedimentation, 2) neutralisation of both the supernatant and algal sediment, and 3) centrifugation of the algal sediment. The material and energy requirements were calculated for these steps using two cases considering different choices of chemicals; case 1: $\mathrm{NaOH}, \mathrm{MgSO}_{4}, \mathrm{HCl}$; and case 2: $\mathrm{Ca}(\mathrm{OH})_{2}, \mathrm{Mg}(\mathrm{OH})_{2}, \mathrm{H}_{3} \mathrm{PO}_{4}$ and compared to just centrifugation. Centrifugation data for all processes were based on a Westfalia clarifier (model 300-96-777) at demonstration scale (Beal et al., 2015; Huntley et al., 2015) with an electricity usage of $35.5 \mathrm{MJ} \mathrm{m}^{-3}$ of liquid processes, maximum harvesting efficiency of $99 \%$ yielding a dry weight content of $20 \%$ (Beal et al., 2015). It was assumed that energy requirement for mixing during the flocculation process and pumping are negligible and that flocculated cells had the same harvesting efficiency as non-flocculated cells (no available empirical data).

Processes were compared in terms of their monetary cost (Euros, $€$ ), non-renewable energy demand (NRED, MJ), renewable energy demand (RED, MJ), global warming potential (GWP, $\mathrm{kg} \mathrm{CO}_{2}$-equivalents), eutrophication potential (EP, g $\mathrm{PO}_{4}$-equivalents) and ozone depletion potential (ODP, kg CFC-11 equivalents). The functional unit for all processes, was for the harvesting of $1 \mathrm{~kg}$ of dry biomass ( $1 \mathrm{~kg} \mathrm{DW})$. No other upstream or downstream processing was considered. The environmental impact of chemicals was taken from EcoInvent version 3.0, while their prices were taken from (Egle et al., 2016). To investigate the impact of different electricity mixes on the harvesting processes, the theoretical production plant was sited in three different locations receiving different electricity mixes: Sweden (mainly nuclear and hydroelectric), Spain (natural gas) and Greece (mainly brown coal and natural gas) (Itten et al., 2014). Impacts of electricity mixes were taken from EcoInvent version 3.0 and a medium voltage power supply was assumed (Weidema et al., 2013). Electricity costs for EU countries were the average industrial electricity prices for medium size consumers (500-2000 MWh) collated by Eurostat (Eurostat statistics explained). Impact values for all chemicals examined in this study are summarised in Supplementary Materials.

\subsection{Statistical analysis}

Differences between multiple treatments were assessed by one-way analysis of variance (ANOVA). If ANOVA results were significant, comparisons between means were made using Tukey's post hoc analysis and the alpha-value was set at 0.01 . Statistical analyses were conducted using SPSS version 22.0 (IBM Corp.) or MODDE Pro (see Section 2.3). 


\section{Results and discussion}

\subsection{Effect of biomass concentration on alkaline and $M g$ flocculation efficiency}

Flocculation of $C$. zofingiensis cultures at $\mathrm{NaOH}$ concentrations of 4, 6 , and $10 \mathrm{mM}$ and 6,8 and $10 \mathrm{mM} \mathrm{MgSO}_{4}$ were conducted to determine the optimal chemical dosing for effective biomass recovery. These were repeated at different biomass concentrations to examine if there is an interaction between biomass concentration and different flocculant levels. Preliminary trials showed these ranges of $\mathrm{NaOH}$ and $\mathrm{MgSO}_{4}$ to be the most effective for flocculation at $1 \mathrm{~g} \mathrm{DW} \mathrm{L}^{-1}$ (Supplementary Materials). When not adding base or $\mathrm{MgSO}_{4}$ (i.e. controls), $<2 \%$ of biomass was recovered after $1 \mathrm{~h}$, regardless of biomass concentration. The maximum biomass recoveries at the three biomass concentrations tested $\left(0.5,1.0\right.$ and $\left.1.6 \mathrm{~g} \mathrm{DW} \mathrm{L}^{-1}\right)$ were found at $8 \mathrm{mM} \mathrm{NaOH}$, but with varying $\mathrm{Mg}^{2+}$ concentrations, and were $82 \%, 93 \%$ and $94 \%$, respectively. The collected empirical data were fitted with a multiple regression model with a logistic transformation of flocculation efficiency to constrain the model data between 0 and $100 \%$. This resulted in the greatest fit, lowest residual standard deviation and highest statistical robustness (Fig. 1, Supplementary Materials). Flocculation efficiency had a significant relationship with all factors $(p<0.01)$. Generally, flocculation efficiency increased as biomass concentration increased (having a significant positive regression coefficient for dry weight, $p<0.0001)$. At the highest base concentration, generally smaller amounts of $\mathrm{Mg}^{2+}$ were required to achieve $>90 \%$ flocculation efficiency. Base concentration accounted for a greater proportion of the variation in flocculation efficiency compared to $\mathrm{MgSO}_{4}$ concentration and biomass concentration. There were no significant $(p>0.05)$ interactions between $\mathrm{MgSO}_{4}$ addition and base, between either $\mathrm{MgSO}_{4}$ addition or base and dry weight or between media $\mathrm{pH}$ and flocculation efficiency ( $p>0.05)$.

When examining the raw data between different dry weights for a given set of $\mathrm{NaOH}$ and $\mathrm{MgSO}_{4}$ concentrations, subtle interactions can be discerned. For instance, at $4 \mathrm{mM} \mathrm{NaOH}$ and $6 \mathrm{mM} \mathrm{MgSO}_{4}$ (the lowest levels examined), high biomass concentrations perform statistically worse than low biomass concentrations for flocculation efficiency $(p<0.01)$. This finding suggests that at high biomass concentrations, a higher $\mathrm{pH}$ or $\mathrm{Mg}^{2+}$ concentration is required to induce flocculation, in agreement with other studies where $\mathrm{Mg}^{2+}$ was used to induce flocculation (Garcia-Perez et al., 2014; Wu et al., 2012). However, at the highest dosing level ( $8 \mathrm{mM} \mathrm{NaOH}$ and $10 \mathrm{mM} \mathrm{MgSO}_{4}$ ), the highest biomass experiment had a statistically greater flocculation efficiency than the low biomass experiment $(p<0.01)$, which was also seen at $6 \mathrm{mM} \mathrm{NaOH}$ and $10 \mathrm{mM} \mathrm{MgSO}_{4}$. These results suggest that there are other factors or interactions influencing sedimentation efficiency beyond just the concentration of materials added, possibly there are simply too few cells to create large enough flocs in the low biomass treatment. Secreted algal organic matter decreases the efficiency of flocculation, even if alkaline flocculation is less affected compared to other methods (Vandamme et al., 2012b). However, cells were centrifuged and washed to remove spent media to avoid such effects. Differences in the cellular composition between the different biomass concentration experiments may affect the flocculation, but cultures were maintained in nutrient replete conditions to prevent changes associated with nutrient stress.

Knowledge of the interaction between biomass density and flocculant is key in designing bioprocesses that are both resource efficient (i.e. minimal chemical usage) and effective for biomass recovery. If biomass concentrations fluctuate over the course of harvesting periods at scale due to variable ambient conditions or operational parameters, careful monitoring of culture density and physiological state may enable the optimal quantity of materials to be added using the models developed herein. However, in this instance, it appears that a base concentration of $8 \mathrm{mM} \mathrm{NaOH}$ and an $\mathrm{Mg}^{2+}$ concentration between 6 and $10 \mathrm{mM}$ are sufficient to achieve maximum flocculation at all the biomass concentrations tested. These experiments used media containing no additional $\mathrm{Mg}^{2+}$; freshwater algal media typically contain $\leq 0.4 \mathrm{mM} \mathrm{Mg}^{2+}$ (Andersen, 2005), so additional Mg is certainly required to achieve high levels of flocculation, whereas in seawater media $\left(\sim 50 \mathrm{mM} \mathrm{Mg}^{2+}\right)$ this is not the case (Mayers et al., 2018).

\subsection{Application at pilot scale and evaluation of subsequent neutralisation}

The process developed at bench scale was examined at pilot scale to ascertain whether this method could be scaled effectively for industrial application. From the flocculation model based on bench-scale data, a dosage of $8 \mathrm{mM} \mathrm{NaOH}$ and $10 \mathrm{mM} \mathrm{MgSO}_{4}$ was predicted to result in the greatest flocculation efficiency at $0.4 \mathrm{~g} \mathrm{DW} \mathrm{L}^{-1}(0.04 \% \mathrm{DW})$. Thus, flocculation at these dosages was evaluated on biomass harvested at approximately $0.4 \mathrm{~g} \mathrm{DW} \mathrm{L}^{-1}$. The $\mathrm{pH}$ was observed to be $11.01 \pm 0.04$ (data from 2 biological replicates) and a flocculation efficiency of $89.4 \pm 2.2 \%$ was achieved with a concentration factor of $8.1 \pm 0.1$. The sediment had a biomass concentration of $3.3 \pm 0.1 \mathrm{~g} \mathrm{DW} \mathrm{L}^{-1}$ $(0.33 \% \mathrm{DW})$ with a volume that was $12.5 \%$ of the volume loaded. These data show that sedimentation efficiency was comparable at pilot scale as for lab scale systems, as the flocculation efficiency at $0.51 \mathrm{~g} \mathrm{~L}^{-1}$ for the same dosing was $88.2 \pm 0.03 \%$.

To allow recycling of the media remaining after sedimentation (supernatant), the acid requirement for neutralisation of the supernatant to $\mathrm{pH} 7$ was determined to be $2.6 \pm 0.1 \mathrm{mM}$ of $\mathrm{HCl}$ (from a
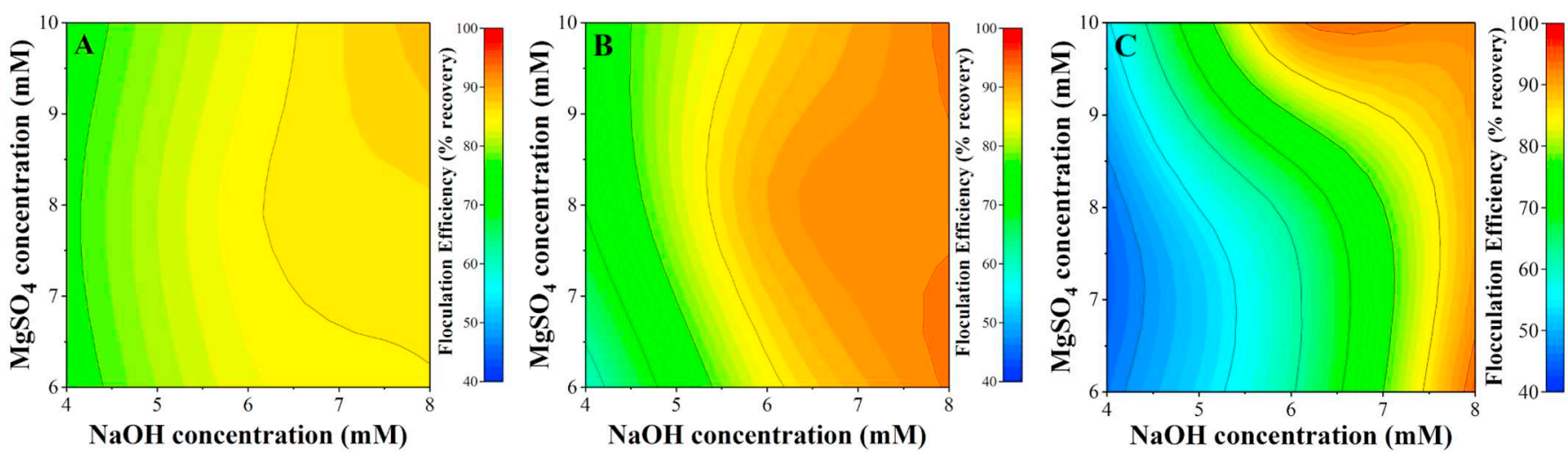

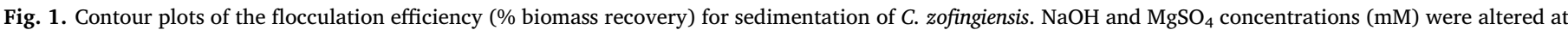

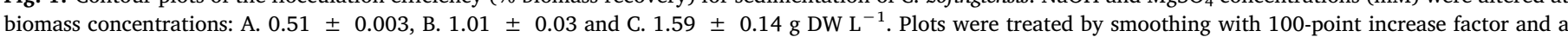

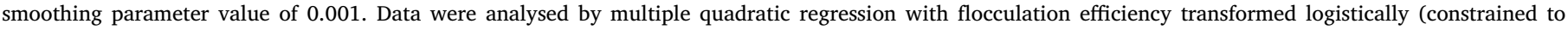
0-100\%) and non-significant model terms removed from the model (Statistics in Supplementary Material). 
Table 1

Biochemical and elemental profile of $C$. zofingiensis biomass (\% DW) from different harvesting processes (analytical replicates: 3 for biochemical and 2 for elemental components).

\begin{tabular}{|c|c|c|c|}
\hline Component (\% DW) & Centrifuged & $\begin{array}{l}\text { Sedimented, non- } \\
\text { neutralised, } \\
\text { centrifuged }\end{array}$ & $\begin{array}{l}\text { Sedimented, } \\
\text { neutralised, } \\
\text { centrifuged }\end{array}$ \\
\hline \multicolumn{4}{|l|}{$\begin{array}{l}\text { Biochemical } \\
\text { components }\end{array}$} \\
\hline Carbohydrates & $6.30 \pm 0.49^{\mathrm{a}}$ & $3.22 \pm 0.22^{b}$ & $5.02 \pm 0.49^{\mathrm{a}}$ \\
\hline Protein & $47.4 \pm 1.70^{\mathrm{a}}$ & $30.5 \pm 0.69^{b}$ & $48.4 \pm 1.41^{\mathrm{a}}$ \\
\hline Chlorophyll $(\mathrm{a}+\mathrm{b})$ & $3.81 \pm 0.22^{\mathrm{a}}$ & $2.09 \pm 0.19^{b}$ & $3.12 \pm 0.10^{c}$ \\
\hline Carotenoids & $0.79 \pm 0.05^{\mathrm{a}}$ & $0.37 \pm 0.03^{b}$ & $0.76 \pm 0.02^{\mathrm{a}}$ \\
\hline Ash & $6.50 \pm 0.70^{a}$ & $31.63 \pm 0.19^{b}$ & $6.28 \pm 0.16^{\mathrm{a}}$ \\
\hline \multicolumn{4}{|l|}{ Elemental components } \\
\hline Hydrogen & $9.81 \pm 0.11^{\mathrm{a}}$ & $6.21 \pm 0.03^{b}$ & $9.86 \pm 0.02^{\mathrm{a}}$ \\
\hline Carbon & $51.67 \pm 0.15^{\mathrm{a}}$ & $32.04 \pm 0.00^{b}$ & $50.80 \pm 0.33^{\mathrm{a}}$ \\
\hline Nitrogen & $7.45 \pm 0.01^{\mathrm{a}}$ & $5.83 \pm 0.03^{b}$ & $7.29 \pm 0.12^{\mathrm{a}}$ \\
\hline Oxygen ${ }^{\dagger, *}$ & $23.79 \pm 0.01$ & $23.44 \pm 0.15$ & $23.84 \pm 0.20$ \\
\hline Sulphur ${ }^{\dagger}$ & $0.79 \pm 0.06$ & $0.92 \pm 0.09$ & $0.91 \pm 0.06$ \\
\hline Sodium & $0.04 \pm 0.01^{\mathrm{a}}$ & $0.23 \pm 0.03^{b}$ & $0.07 \pm 0.01^{\mathrm{a}}$ \\
\hline Magnesium & $0.41 \pm 0.11^{\mathrm{a}}$ & $9.07 \pm 0.03^{b}$ & $0.55 \pm 0.02^{\mathrm{a}}$ \\
\hline Phosphorus & $1.72 \pm 0.01^{\mathrm{a}}$ & $3.15 \pm 0.03^{b}$ & $1.53 \pm 0.12^{\mathrm{a}}$ \\
\hline Potassium & $1.46 \pm 0.03^{\mathrm{a}}$ & $0.60 \pm 0.18^{b}$ & $1.08 \pm 0.04^{\mathrm{a}}$ \\
\hline Calcium & $0.14 \pm 0.01^{\mathrm{a}}$ & $0.84 \pm 0.09^{b}$ & $0.22 \pm 0.02^{c}$ \\
\hline Iron $^{\dagger}$ & $0.07 \pm 0.01$ & $0.06 \pm 0.03$ & $0.10 \pm 0.02$ \\
\hline
\end{tabular}

Different letters represent statistically significant differences between treatments at an alpha value of 0.01. Tested using one-way ANOVA with Tukey's post-hoc test. 'Denotes non-significant differences between treatments. *Oxygen was calculated from the sum of 100-C-N-H-S-ash.

starting $\mathrm{pH}$ of $11.1 \pm 0.2$ ) and for the biomass sediment $80.0 \pm 0.1 \mathrm{mM}$ of $\mathrm{HCl}$. Neutralising to a higher (but still acceptable) $\mathrm{pH}$ of the sediment would significantly decrease the acid requirement (e.g. $70 \mathrm{mM} \mathrm{HCl}$ to $\mathrm{pH} 8.0$ ), which would have a clear cost benefit; however, the environmental impacts and the efficacy of the salt precipitation and removal process would need assessment. This work does not empirically consider the reuse of process water for further cultivation; however, several studies have demonstrated its feasibility (Castrillo et al., 2013; Wu et al., 2012).

To evaluate whether neutralisation of the sediment was effective for the removal of precipitants such as $\mathrm{Mg}$, the elemental composition was evaluated (Table 1). Centrifuged, non-neutralised biomass had a significantly greater concentration of $\mathrm{Mg}, \mathrm{Ca}, \mathrm{Na}$ and $\mathrm{P}$, with $\mathrm{Mg}$ having the greatest increase (22-fold) compared to directly centrifuged (untreated) biomass. Centrifuged neutralised biomass had approximately the same elemental composition as untreated biomass with regards to $\mathrm{Mg}, \mathrm{Na}, \mathrm{P}$ and other elements $(p>0.01$ ), however, Ca remained significantly higher $(p<0.01)$. In contrast, a lower Ca content was previously observed in Chlorella vulgaris that was neutralised in comparison to biomass before flocculation and neutralisation, which was attributed to precipitation of calcium carbonates as the $\mathrm{pH}$ increased due to photosynthetic activity (Vandamme et al., 2015). Since the processes in this study were performed rapidly and, when appropriate, sediments were stored refrigerated in the dark to avoid changes in composition and growth, we did not observe this phenomenon. We assume another mechanism is responsible for the increase in $\mathrm{Ca}$ in this sample, since $\mathrm{C}$ content is the same as in the original biomass (Table 1; $p>0.01$ ), indicating no increase in carbonates in the biomass.

The biochemical composition of harvested material was evaluated to examine if the sedimentation process had a negative impact on the biomass quality (Table 1 ). Non-neutralised biomass had an ash content 4.9-fold greater than the control $(p<0.01)$, but neutralisation decreased the ash content to the same level as the control. It is expected that this increase in ash content corresponds to the salts and hydroxides precipitated with the biomass. The concentration of protein, carbohydrates, total carotenoids and all elemental components was also the same for control and neutralised biomass $(p>0.01)$. The only significant difference was seen for total chlorophyll content, which was significantly lower in the neutralised biomass compared to the control $(p<0.01)$.

\subsection{Flocculation mechanism}

The flocculation/sedimentation mechanism includes formation of $\mathrm{Mg}(\mathrm{OH})_{2}$ as supported by an absorption band of the $\mathrm{OH}$ stretch at approx. $3700-3695 \mathrm{~cm}^{-1}$ in the infrared spectra which was present in sedimented biomass that was not neutralised, but absent in neutralised biomass; this peak was still seen after thorough washing (Supplementary Materials). Formation of $\mathrm{Mg}(\mathrm{OH})_{2}$ is also supported by the increase in $\mathrm{Mg}$ in the sedimented biomass (Table 1$). \mathrm{Mg}(\mathrm{OH})_{2}$ forms at approximate $\mathrm{pH} 10.5$ and is positively charged up to $\mathrm{pH} 11.5$. Both surface charge neutralisation and sweeping can be contributing to the flocculation mechanism and these correlate or are independent of biomass concentration, respectively (Brady et al., 2014; Garcia-Perez et al., 2014). In our trials, the $\mathrm{pH}$ was $\sim 11$ and there was a strong dependence on biomass concentration (model coefficient of 4.9, Supplementary Materials), and thus we believe that neutralisation of the negative cell surface is the main mechanism in action. Several studies have highlighted the role of $\mathrm{Mg}(\mathrm{OH})_{2}$ in alkaline flocculation (Vandamme et al., 2015; Vandamme et al., 2012a), but several other studies have also suggested calcium phosphates (formed at $>\mathrm{pH}$ 9.0) contributing to surface charge neutralisation and flocculation (Beuckels et al., 2013; Sukenik and Shelef, 1984). Since there was a significant increase in Ca and P in sedimented biomass, precipitation of calcium phosphates may also contribute to the flocculation mechanism. Variations in media ion concentrations and flocculation $\mathrm{pH}$ will have an impact on the exact mechanism of flocculation and which salts that coprecipitate with the biomass.

\subsection{Opportunities for cost saving?}

To determine if cheaper input sources of base and $\mathrm{Mg}^{2+}$ (other than $\mathrm{NaOH}$ and $\mathrm{MgSO}_{4}$ ) could be utilised for flocculation and sedimentation of $C$. zofingiensis, biomass recovery was examined using $\mathrm{Ca}(\mathrm{OH})_{2}$ and $\mathrm{Mg}(\mathrm{OH})_{2}$ (costs see Supplementary Materials). Additionally, $\mathrm{Mg}(\mathrm{OH})_{2}$ acts as a base, which potentially decreases base requirements. This combination was examined at approx. $1 \mathrm{~g} \mathrm{DW} \mathrm{L} \mathrm{L}^{-1}$ biomass concentration, 2, 4 and $6 \mathrm{mM} \mathrm{Ca}(\mathrm{OH})_{2}$ and 4, 6 , and $8 \mathrm{mM} \mathrm{Mg}(\mathrm{OH})_{2}$ in an experimental design (22 individual sedimentations, incl. 5 replicates of the centre point). A maximum flocculation efficiency of $\sim 98 \%$ biomass recovery was achieved after $1 \mathrm{~h}$ using $4 \mathrm{mM} \mathrm{Ca}(\mathrm{OH})_{2}$ and $4 \mathrm{mM} \mathrm{Mg}$ $(\mathrm{OH})_{2}$ (Fig. 2D). The cost of these additives in comparison to the cost of $\mathrm{NaOH} / \mathrm{MgSO}_{4}$ system ( $93 \%$ flocculation efficiency at $8 \mathrm{mM} \mathrm{NaOH}$ and $6 \mathrm{mM} \mathrm{MgSO}_{4}$ ) was halved when assessing the necessary flocculant additions to a $10 \mathrm{~m}^{3}$ tank, i.e. $1.8 €$ versus $0.95 €$ (prices used see Supplementary Materials). Potentially, even lower costs can be obtained for the $\mathrm{Ca}(\mathrm{OH})_{2} / \mathrm{Mg}(\mathrm{OH})_{2}$ system since for similar efficiency at $93 \%$, less flocculants would be needed. At $\mathrm{Ca}(\mathrm{OH})_{2}$ concentrations of $2 \mathrm{mM}$, flocculation efficiency was $<90 \%$ regardless of $\mathrm{Mg}(\mathrm{OH})_{2}$ concentration. The quadratic model generated from these data, showed that $\mathrm{Ca}(\mathrm{OH})_{2}$ concentration was the major factor influencing flocculation $\left(p<0.0001\right.$; Supplementary Materials), whereas $\mathrm{Mg}(\mathrm{OH})_{2}$ concentration had only a small impact $(0.05<p>0.01)$. This analysis would indicate that $\mathrm{Mg}^{2+}$ addition could have been decreased further, however, FTIR scans of biomass flocculated using $\mathrm{Ca}(\mathrm{OH})_{2} / \mathrm{Mg}(\mathrm{OH})_{2}$ showed that $\mathrm{Mg}(\mathrm{OH})_{2}$ is still present in the sediment (Supplementary Materials). For a comparable biomass concentration, when using $\mathrm{NaOH} / \mathrm{MgSO}_{4}$, a similar phenomenon was seen at $8 \mathrm{mM} \mathrm{NaOH}$, as there was no significant difference in flocculation efficiency at any tested $\mathrm{Mg}^{2+}$ concentration (Fig. 1B). However, at higher biomass concentrations, higher $\mathrm{Mg}^{2+}$ concentrations were found to be necessary for the $\mathrm{NaOH} / \mathrm{MgSO}_{4}$ system, but this was not investigated for $\mathrm{Ca}(\mathrm{OH})_{2} / \mathrm{Mg}$ 

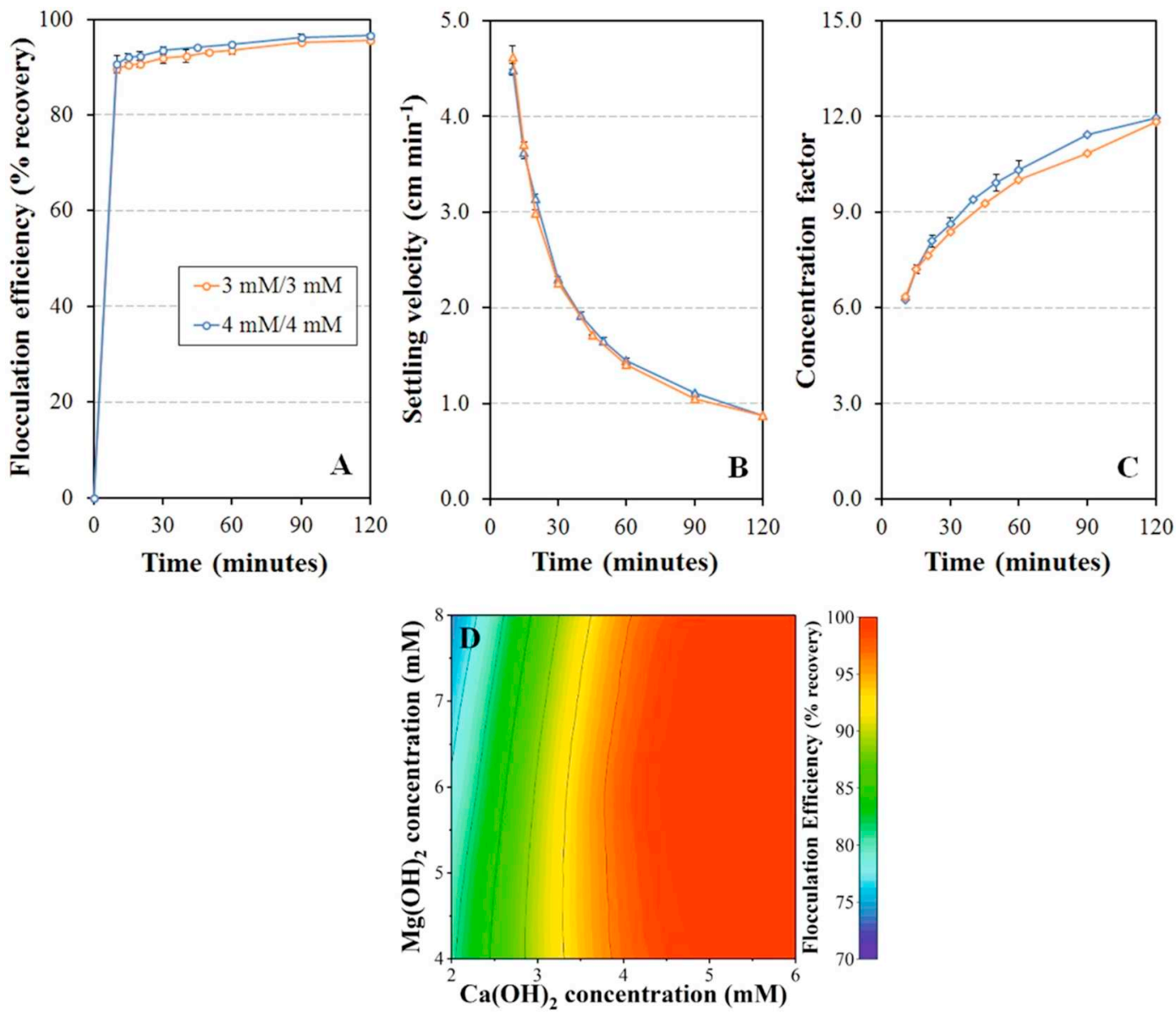

Fig. 2. Detailed temporal profiling of sedimentation, A. flocculation efficiency, B. settling velocity, C. concentration factor, of C. zofingiensis using $\mathrm{Ca}(\mathrm{OH})_{2}$ and $\mathrm{Mg}$ $(\mathrm{OH})_{2}$ either with both at $3 \mathrm{mM}$ (blue line) or $4 \mathrm{mM}$ (orange line). Each treatment was performed in duplicate with triplicate absorbance measurements. D. Contour plot of the flocculation efficiency using $\mathrm{Mg}(\mathrm{OH})_{2}$ and $\mathrm{Ca}(\mathrm{OH})_{2}$ at a biomass concentration of $0.97 \pm 0.04 \mathrm{~g} \mathrm{~L}^{-1}$. The treatment of the plot was similar as described in Fig. 1. (For interpretation of the references to colour in this figure legend, the reader is referred to the web version of this article.)

$(\mathrm{OH})_{2}$. Interestingly, for the flocculation of $C$. zofingiensis using $\mathrm{NaOH} /$ $\mathrm{MgSO}_{4}$ at a comparable biomass concentration, there was found to be no significant correlation between $\mathrm{pH}$ and flocculation efficiency $\left(p>0.01, r^{2}=0.43\right)$, whereas for $\mathrm{Ca}(\mathrm{OH})_{2} / \mathrm{Mg}(\mathrm{OH})_{2}, \mathrm{pH}$ and flocculation efficiency had a significant polynomial relationship $\left(p<0.01, r^{2}=0.99\right)$, which further strengthens the hypothesis that a different mechanism was responsible in this second case.

The concentration factors achieved for $\mathrm{Ca}(\mathrm{OH})_{2} / \mathrm{Mg}(\mathrm{OH})_{2}$ were comparable to those achieved for $\mathrm{NaOH} / \mathrm{MgSO}_{4}$ (approx. 7-9 $\times$ ), and previous results for $C$. zofingiensis using $\mathrm{Mg}^{2+}$ addition and alkaline flocculation (Zhang et al., 2016). However, significantly higher concentration factors were found, 31 for $C$. vulgaris using $\mathrm{NaOH}$ at $3 \mathrm{mM}$ for induction of flocculation, but this may be ascribed to differences in media salt concentrations resulting in different amounts of co-precipitating salts forming thereby changing sediment volume (GarciaPerez et al., 2014; Lama et al., 2016). For instance, the media used by Lama et al. contained just $1.5 \mathrm{mg} \mathrm{P} \mathrm{L}{ }^{-1}$, whereas the BBM media used here contained $50 \mathrm{mg} \mathrm{P} \mathrm{L}{ }^{-1}$. A greater volume of precipitant in the sediment decreases the concentration factor. Alternatively, it could be the results of species or physiological related differences in floc characteristics and interactions with precipitants.

To further optimise this process for $\mathrm{Ca}(\mathrm{OH})_{2}$ and $\mathrm{Mg}(\mathrm{OH})_{2}$, flocculation efficiency, settling speed and concentration factor were examined at $4 \mathrm{mM}$ of flocculants in greater temporal detail. Rapid processing speeds and high functional performance are often important to reduce infrastructure costs (Vandamme et al., 2013). In sedimentation cones using $250 \mathrm{~mL}$ of culture $\left(\sim 1.0 \mathrm{~g} \mathrm{DW} \mathrm{L}^{-1}\right), 90 \%$ of cells had flocculated within $10 \mathrm{~min}$ and settling velocity was maximal (Fig. 2A-C). The percentage of recovered cells increased to approx. 95\% after $1 \mathrm{~h}$ and only increased slightly after $2 \mathrm{~h}$ (Fig. 2A). However, the concentration factor continued to increase over time, from approx. a $10 \times$ concentration factor at $1 \mathrm{~h}$, to $12 \times$ concentration at $2 \mathrm{~h}$, with an indication that it would have further increased with greater time remaining (Fig. 2C). The time cost incurred by increasing concentration factor could increase the likelihood of loss of cellular integrity or metabolite destruction (due to the high $\mathrm{pH}$ or contamination), or the requirement for a greater infrastructure processing capacity. However, the decrease in centrifuge volume could result in additional savings downstream in the process. These concentrations factors are ultimately quite low and the factors preventing higher concentration factors from being achieved should be investigated. Sedimentation using $\mathrm{Ca}(\mathrm{OH})_{2}$ and $\mathrm{Mg}(\mathrm{OH})_{2}$ at concentrations of $3 \mathrm{mM}$ was also tested to verify the model prediction of comparable flocculation efficiencies, which was found to be the case (no significant difference, $p>0.01$; Fig. 2A-C).

Neutralisations of the sediment and supernatant for the $4 \mathrm{mM} \mathrm{Ca}$ $(\mathrm{OH})_{2} / \mathrm{Mg}(\mathrm{OH})_{2}$ treatment was performed by titration with $0.5 \mathrm{M}$ $\mathrm{H}_{3} \mathrm{PO}_{4}$, and it was determined that 8.36 and $2.49 \mathrm{mM} \mathrm{H}_{3} \mathrm{PO}_{4}$ was required to return these fractions to $\mathrm{pH} 7.0$, respectively. This would return 259.9 and $77.2 \mathrm{mg} \mathrm{L}^{-1}$ of $\mathrm{P}$ back to the cultivation system if these waters were recycled assuming all $\mathrm{H}_{3} \mathrm{PO}_{4}$ added forms dissolved $\mathrm{PO}_{4}$ and is not associated with the biomass (as seen for $\mathrm{NaOH}$ flocculated biomass neutralised with $\mathrm{HCl}$ ). However, the concentration of $\mathrm{P}$ and $\mathrm{Mg}$ in the biomass neutralised using $\mathrm{H}_{3} \mathrm{PO}_{4}$ was not measured and it is possible that at the higher concentrations of $\mathrm{P}, \mathrm{Mg}$ and $\mathrm{Ca}$ in this 
system, some of these could be lost due to precipitation as calcium or magnesium salts, or even as struvite with $\mathrm{NH}_{4}$. This could influence the removal of these elements from the biomass and prevent their recycling, emphasising the complex nature of the interaction and the influence of concentration, mineral ratios, temperature and $\mathrm{pH}$. For the benefit of our process model, it was assumed that recovery of $\mathrm{P}$ and $\mathrm{Mg}$ from the biomass was $95 \%$ to reflect loss to precipitation. Furthermore, the biochemical composition of the biomass was assumed to be affected in the same way when either of $\mathrm{HCl}$ and $\mathrm{H}_{3} \mathrm{PO}_{4}$ was used as neutralising agents. Further studies should investigate these aspects in greater detail.

\subsection{Cost and life-cycle impact assessment of a two-step harvesting process}

To assess the effectiveness of a two-step harvesting process in decreasing the costs, energy usage and the environmental impact of biomass recovery; operating cost and life cycle analyses were performed. A baseline case of centrifugation was included as well as both chemical choices, with case 1 being: $\mathrm{NaOH}, \mathrm{MgSO}_{4}$ and $\mathrm{HCl}$, while case 2 was: $\mathrm{Ca}$ $(\mathrm{OH})_{2}, \quad \mathrm{Mg}(\mathrm{OH})_{2}$ and $\mathrm{H}_{3} \mathrm{PO}_{4}$ (impacting less than $\mathrm{HCl}$, see Supplementary Materials). These analyses only assessed biomass harvesting and did not include any processes up-stream (i.e. cultivation) or further downstream processing, such as drying. Empirical data from this study for sedimentation of $1 \mathrm{~g} \mathrm{~L}^{-1}$ cultures were used. Since centrifugation requires considerable electrical energy it was prudent to evaluate the impact of electricity mix (coal vs. gas vs. nuclear vs. hydroelectric, etc.) on the process and, thus, three representative European countries were selected. These were Sweden, with a low cost and global warming potential (GWP) electricity mix (mainly nuclear and hydroelectric), Greece, with a high reliance on fossil resources with a high GWP (mainly brown coal and natural gas), and Spain, with an intermediate mixture in terms of GWP (mainly natural gas) (Itten et al., 2014).

The result of the cost analysis showed the impact of these different processes varied significantly depending on both configuration and location. Two-step harvesting performed best in terms of cost per $\mathrm{kg}$ DW versus centrifugation, especially in Spain and Greece where electricity prices are higher $\left(\sim 0.031 € \mathrm{MJ}^{-1}\right.$; Fig. $\left.3 \mathrm{~A}\right)$, whereas in Sweden the costs are more comparable since electricity is nearly half the price $\left(0.017 € \mathrm{MJ}^{-1}\right)$. Costs for the base case (solely centrifugation) were high for both Spain and Greece Prices of $\left(>1 € \mathrm{~kg} \mathrm{DW}^{-1}\right)$, whereas all two-step processes had costs of $<0.52 € \mathrm{~kg} \mathrm{DW}^{-1}$ with only minor differences between the different countries, due to a decreased reliance on electricity ( $90 \%$ less vs. base case). Two-step case 1 was found to be approx. $17-19 \%$ cheaper than case 2, due to the higher price of $\mathrm{H}_{3} \mathrm{PO}_{4}$ versus $\mathrm{HCl}$. Overall, the cost of centrifugation accounts for $13-28 \%$ of the total cost of the two-step processes cases across the different locations.

In terms of GWP, Sweden again performed better for all processes than the other locations, with the two-step processes being more impactful than centrifugation alone (Fig. 3B). Chemical production has higher associated GWPs than electricity; and the electricity mix in Sweden has 10-20 times lower GWP than Greece or Spain (Supplementary Materials). However, in Spain and Greece, a two-step process would decrease GHG emissions compared to centrifugation alone. Case 2 performed better (33-47\% lower GWP) than case 1 since the production of $\mathrm{HCl}$ is highly impactful and double that of $\mathrm{H}_{3} \mathrm{PO}_{4}$ (Supplementary Materials). There is a large spread in the energy usage of the different processes and locations (Fig. 3C, D). Differences in electricity mix resulted in substantial variations across locations for the base case, with an inverse relationship between the three locations with regards to Non-Renewable and Renewable energy Demand (NRED and RED). There are significantly less differences between countries for two-step processes, with Case 2 being particularly efficient, both for NRED and RED, due to production of both $\mathrm{Ca}(\mathrm{OH})_{2}$ and $\mathrm{Mg}(\mathrm{OH})_{2}$ being less energy intensive per mass compared to $\mathrm{NaOH}$ and $\mathrm{MgSO}_{4}$. If it is assumed that the energy content of algal biomass is approximately $20 \mathrm{MJ} \mathrm{kg}$ $\mathrm{DW}^{-1}$, the cumulative energy demand (CED) for harvesting using centrifugation and case 1 surpass this in all locations at least 3-fold, while case 2 has a CED slightly larger than the biomass energy content. It is hence imperative that harvesting processes become more efficient to improve the energy return on investment to make bioenergy applications more feasible. There were very large differences in the eutrophication potential of these processes (Fig. 3E). Those located in Greece were especially impactful owing to the significant surface water damage and soil erosion caused by brown coal usage (Theodosiou et al., 2014). Case 1 has a marginally higher impact compared to case 2, which is due to the impact of $\mathrm{NaOH}$ use versus $\mathrm{Ca}(\mathrm{OH})_{2}$. Ozone depletion was rather unaffected related to the different locations since the electricity mixes have approx. the same impact $\left(1.5-1.7 \times 10^{6} \mathrm{~kg}\right.$ CFC11 eq $\mathrm{MJ}^{-1}$ ). Ozone depletion was significantly worse for case 1 (Fig. 3F), due to the use of $\mathrm{NaOH}$ and $\mathrm{HCl}$ that have up to 100 times higher ODP than the other chemicals (Supplementary Materials), presumably due to the involvement of chlorine in production.

The material requirements found in this study for efficient sedimentation were comparable to processes presented in other studies (Vandamme et al., 2015; Vandamme et al., 2012a). However, differences in the choice of materials, the quantities required for neutralisation, and costs of the materials used result in significant differences in the estimated costs, e.g. in the total cost of $€ 0.051$ per $\mathrm{kg}$ DW estimated for flocculation $\left(\mathrm{Ca}(\mathrm{OH})_{2}\right.$ and $\left.\mathrm{HCl}\right)$, the neutralisation of the supernatant was not included (Vandamme et al., 2015). In comparison, our results predict a higher material cost of $0.35-0.38 € \mathrm{~kg} \mathrm{DW}^{-1}$ for case 1 and $0.44-0.47 € \mathrm{~kg} \mathrm{DW}^{-1}$ for case 2 inputs, but these include the neutralisation. Comprehensive LCA of sedimentation processes are somewhat limited for alkaline-induced flocculation techniques, but a two-step process utilising alum followed by centrifugation had process energy costs of 1.2-1.4 $\mathrm{MJ} \mathrm{kg} \mathrm{DW}{ }^{-1}$ depending on the biomass concentration (Weschler et al., 2014), which compares to 59.3-62.6 and 17.6-20.8 MJ kg DW ${ }^{-1}$ for case 1 and 2, respectively, in this study. However, the previous study did not include the energy demand of material or electricity production, used outdated and optimistic energy requirements for centrifugation, and did not consider the removal of alum before utilisation of biomass.

For case 1 , if it was assumed that $\mathrm{Mg}$ could be recycled, this would meet all $\mathrm{Mg}$ requirements for cultivation, but these savings are less significant since $\mathrm{MgSO}_{4}$ has comparatively less impact than the other chemicals. In case 2 , the use of $\mathrm{H}_{3} \mathrm{PO}_{4}$ for neutralisation enables recycling of $\mathrm{P}$ back to cultivation, which could result in significant savings by mitigation of P-fertiliser requirements, which although relatively minor, 0.1-2 $\mathrm{g} \mathrm{P} \mathrm{kg} \mathrm{DW}^{-1}$, (Mayers et al., 2017), decreases reliance on a costly and finite resource. To ascertain the benefit of recycling nutrients ( $\mathrm{Mg}$ and $\mathrm{P}$ ) from the harvesting back to cultivation, a case 3 as an expansion of case 2 was established. The percentage of nutrient in the media that could be replaced was calculated for case 1 and 2 and $95 \%$ of $\mathrm{P}$ from $\mathrm{H}_{3} \mathrm{PO}_{4}$ and $\mathrm{Mg}$ from $\mathrm{Mg}(\mathrm{OH})_{2}$ was assumed to be recycled back to the culture. This would replace approx. $42 \%$ and $63 \%$ of media $\mathrm{P}$ and $\mathrm{Mg}$ requirements, respectively, based the biomass elemental content found in Table 1 and a harvesting rate of $0.2 \mathrm{~d}^{-1}$. Exclusion of these percentages of the chemicals (instead effectively assigned to biomass production), i.e. case 3 , resulted in $45-48 \%$ decrease in cost $\left(0.23-0.25 € \mathrm{~kg} \mathrm{DW}^{-1}\right)$, a $28-45 \%$ decrease in NRED, GWP and ODP, and an $11-18 \%$ decrease in NED (Fig. 3). These savings increase the benefits associated with case 3 versus the base case, even versus the Swedish model, for which only EP and GWP are still lower for centrifugation. This strategy results in considerable improvements in the overall process for case 3 if nutrient recycling from two-step harvesting is implemented, highlighting the benefits of smart process design and chemical selection.

Overall, these analyses have shown the benefits of developing a twostep harvesting method utilising alkaline flocculation. We are aware that the energy requirements for centrifugation reported in the 


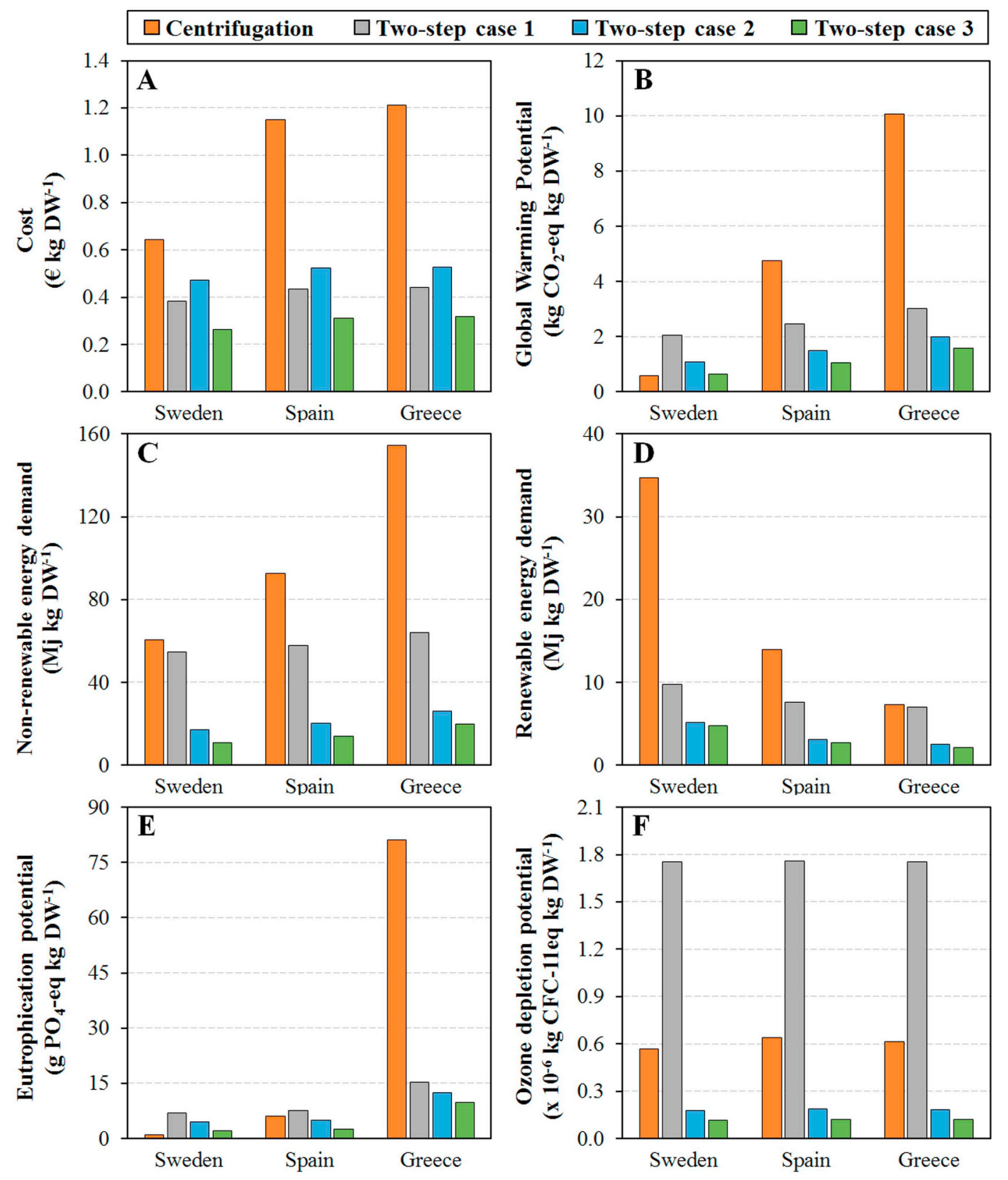

Fig. 3. Impact of C. zofingiensis harvesting process configuration on A. cost, B. global warming potential, C. non-renewable energy demand, D. renewable energy demand, E. eutrophication potential, and F. ozone depletion potential. Baseline case assumes the use of centrifugation only, while two different two-step processes were assessed: Case 1 utilised $\mathrm{NaOH}, \mathrm{MgSO}_{4}$ and $\mathrm{HCl}$, while Case 2 utilised $\mathrm{Mg}(\mathrm{OH})_{2}, \mathrm{Ca}(\mathrm{OH})_{2}$ and $\mathrm{H}_{3} \mathrm{PO}_{4}$. Case 3 uses the case 2 chemicals but includes nutrient recycling. All analyses were based on bench scale data from Sections 3.1 and 3.4.

literature vary quite significantly and thus our findings for the two-step processes could appear better or worse depending on the value utilised. The values of energy requirement for centrifugation in the literature were reported up to $35.5 \mathrm{MJ} \mathrm{m}^{-3}$, with the lowest value of approx. $9 \mathrm{MJ} \mathrm{m}{ }^{-3}$ reported for Evodos' spiral plate centrifuges (Monte et al., 2018). This study used the higher value of $35.5 \mathrm{MJ} \mathrm{m}^{-3}$, which were from trials using commercially available equipment at a large-scale algal production facility (Beal et al., 2015; Huntley et al., 2015) and is thus most appropriate in this context. The use of a less energy intensive centrifugation could decrease the impact of a one-step harvesting process and thus using the value of $9 \mathrm{MJ} \mathrm{m}^{-3}$, the cost of the base case would be decreased by $75 \%$, making its impacts more comparable to case 1 (Supplementary Materials). If nutrient recycling is included, case 3 still performed better across all impact categories for Spain and Greece, and on cost, energy usage and ODP against Sweden.
Subsequently, the development of more efficient centrifuges may negate the use of a two-step process in countries with cheap electricity with a low environmental impact.

One final consideration is the processing time required, i.e. from bioreactor to algal paste, and the impact this may have on process choice if this is a critical factor of production (e.g. especially valuable and sensitive biomass). In the case of the two-step method described, at least $90 \mathrm{~min}$ are likely required to generate a sediment that has been neutralised and ready for centrifugation (regardless of the volume required). A $10 \times$ concentration factor would significantly decrease the centrifugation time, which frees up capacity (i.e. fewer centrifuges). However, for relatively small volumes, the centrifuge considered in this case $\left(3.75 \mathrm{~m}^{3} \mathrm{hr}^{-1}\right)$ would process cultures faster than a two-step process, up to culture volumes of 6-7 $\mathrm{m}^{-3}$ (data not shown). For greater volumes, a larger capacity centrifuge would be required to 
decrease processing time versus a two-step process. Cost of centrifuges most likely far surpasses that of the comparable equipment for sedimentation and hence, there is a careful balance in the selection of process and equipment to match the scale of biomass production with the capacity for downstream processing, both on a capital and operational cost basis. This would require further study to investigate this interplay.

\section{Conclusions}

This study has found that $C$. zofingiensis can be flocculated effectively by supplementing with $\mathrm{Mg}$ and addition of base with similar efficiency both at bench- and pilot scale and that formation of $\mathrm{Mg}(\mathrm{OH})_{2}$ has a role in the mechanism. Alternative chemicals for flocculating and subsequent neutralisation were evaluated to reduce environmental impact and possibility to recycle nutrients and water. Process modelling of flocculation/neutralisation preceded centrifugation harvesting with cases using alternatives of chemicals was compared to solely centrifugation. The modelling showed that results are sensitive for selection of electricity mix and used chemicals in relation to impact categories evaluated.

\section{Declaration of author contributions}

JM, MJA and EA conceived and designed the study. JM, ARL and MJA performed growth and flocculation experiments. JM performed analysis and interpretation of the data. JM and EA drafted the manuscript with contributions and critical revisions from ARL and MJA. EA obtained funding to perform the majority of this work. Final approval for submission was decided by EA.

\section{Declaration of competing interest}

The authors declare that they have no known competing financial interests or personal relationships that could have appeared to influence the work reported in this paper.

\section{Acknowledgments}

The authors would like to thank our colleagues, Dr. Tracey Beacham, Paul Rooks, Dr. Matty Janssen, Dr. Anna Ekman-Nilsson, Javier Sancho-Alcaide, Eric Malmhäll-Bah, Dr. Julia Lind, and Joakim Olsson and Heliospectra AB (Gothenburg), especially Johan Lindqvist, for the loan of LED lamps for pilot trials.

Funding: This work was supported to JJM and EA by FORMAS (the Swedish Research Council for Environment, Agricultural Sciences and Spatial Planning), Sweden, [BioBUF project, 213-2013-78] and to MA by Innovate UK, UK, [IB Catalyst, 352754-395134].

\section{Appendix A. Supplementary data}

Supplementary data to this article can be found online at https:// doi.org/10.1016/j.biteb.2019.100358.

\section{References}

Andersen, R.A., 2005. Algal Culturing Techniques. Elsevier Academic Press, London, UK. Beal, C.M., Gerber, L.N., Sills, D.L., Huntley, M.E., Machesky, S.C., Walsh, M.J., Tester, J.W., Archibald, I., Granados, J., Greene, C.H., 2015. Algal biofuel production for fuels and feed in a 100-ha facility: a comprehensive techno-economic analysis and life cycle assessment. Algal Res. 10, 266-279.

Beuckels, A., Depraetere, O., Vandamme, D., Foubert, I., Smolders, E., Muylaert, K., 2013. Influence of organic matter on flocculation of Chlorella vulgaris by calcium phosphate precipitation. Biomass Bioenergy 54, 107-114.

Brady, P.V., Pohl, P.I., Hewson, J.C., 2014. A coordination chemistry model of algal autoflocculation. Algal Res. 5, 226-230.

Branyikova, I., Prochazkova, G., Potocar, T., Jezkova, Z., Branyik, T., 2018. Harvesting of microalgae by flocculation. Fermentation 4, 93.
Castrillo, M., Lucas-Salas, L.M., Rodriguez-Gil, C., Martinez, D., 2013. High pH-induced flocculation-sedimentation and effect of supernatant reuse on growth rate and lipid productivity of Scenedesmus obliquus and Chlorella vulgaris. Bioresour. Technol. 128, 324-329.

Dassey, A.J., Theegala, C.S., 2013. Harvesting economics and strategies using centrifugation for cost effective separation of microalgae cells for biodiesel applications. Bioresour. Technol. 128, 241-245.

Egle, L., Rechberger, H., Krampe, J., Zessner, M., 2016. Phosphorus recovery from municipal wastewater: an integrated comparative technological, environmental and economic assessment of P recovery technologies. Sci. Total Environ. 571, 522-542.

Eurostat statistics explained Electricity Prices, Second Half of Year, 2014-2016 (EUR per kWh) YB17. WWW document. https://ec.europa.eu/eurostat/statistics-explained/ index.php/File:Electricity_prices,_second_half_of_year,_2014-2016_(EUR_per_kWh) _YB17.png.

Garcia-Perez, J.S., Beuckels, A., Vandamme, D., Depraetere, O., Foubert, I., Parra, R., Muylaert, K., 2014. Influence of magnesium concentration, biomass concentration and $\mathrm{pH}$ on flocculation of Chlorella vulgaris. Algal Res. 3, 24-29.

Gerardo, M.L., Van Den Hende, S., Vervaeren, H., Coward, T., Skill, S.C., 2015. Harvesting of microalgae within a biorefinery approach: a review of the developments and case studies from pilot-plants. Algal Res. 11, 248-262.

Hamilton, M.L., Warwick, J., Terry, A., Allen, M.J., Napier, J.A., Sayanova, O., 2015. Towards the industrial production of omega-3 long chain polyunsaturated fatty acids from a genetically modified diatom Phaeodactylum tricornutum. PLoS One 10, e0144054.

Hathwaik, L.T., Redelman, D., Samburova, V., Zielinska, B., Shintani, D.K., Harper, J.F., Cushman, J.C., 2015. Transgressive, reiterative selection by continuous buoyant density gradient centrifugation of Dunaliella salina results in enhanced lipid and starch content. Algal Res. 9, 194-203.

Huntley, M.E., Johnson, Z.I., Brown, S.L., Sills, D.L., Gerber, L., Archibald, I., Machesky, S.C., Granados, J., Beal, C., Greene, C.H., 2015. Demonstrated large-scale production of marine microalgae for fuels and feed. Algal Res. 10, 249-265.

Itten, R., Frischknecht, R., Stucki, M., 2014. Life Cycle Inventories of Electricity Mixes and Grid. Paul Scherrer Institut (PSI) Version 1.3, treeze Ltd., fair life cycle thinking. www.treeze.ch.

Lama, S., Muylaert, K., Karki, T.B., Foubert, I., Henderson, R.K., Vandamme, D., 2016. Flocculation properties of several microalgae and a cyanobacterium species during ferric chloride, chitosan and alkaline flocculation. Bioresour. Technol. 220, 464-470.

Mayers, J.J., Nilsson, A.E., Albers, E., Flynn, K.J., 2017. Nutrients from anaerobic digestion effluents for cultivation of the microalga Nannochloropsis sp - impact on growth, biochemical composition and the potential for cost and environmental impact savings. Algal Res. 26, 275-286.

Mayers, J.J., Vaiciulyte, S., Malmhäll-Bah, E., Alcaide-Sancho, J., Ewald, S., Godhe, A., Ekendahl, S., Albers, E., 2018. Identifying a marine microalgae with high carbohydrate productivities under stress and potential for efficient flocculation. Algal Res. 31, 430-442.

Monte, J., Sa, M., Galinha, C.F., Costa, L., Hoekstra, H., Brazinha, C., Crespo, J.G., 2018 Harvesting of Dunaliella salina by membrane filtration at pilot scale. Sep. Purif. Technol. 190, 252-260.

Muto, M., Nojima, D., Yue, L., Kanehara, H., Naruse, H., Ujiro, A., Yoshino, T., Matsunaga, T., Tanaka, T., 2017. Potential of water surface-floating microalgae for biodiesel production: Floating-biomass and lipid productivities. J. Biosci. Bioeng. 123, 314-318.

Ruiz, J., Olivieri, G., de Vree, J., Bosma, R., Willems, P., Reith, J.H., Eppink, M.H.M., Kleinegris, D.M.M., Wijffels, R.H., Barbosa, M.J., 2016. Towards industrial products from microalgae. Energy Environ. Sci. 9, 3036-3043.

Smith, B.T., Davis, R.H., 2012. Sedimentation of algae flocculated using naturally-available, magnesium-based flocculants. Algal Res. 1, 32-39.

Sukenik, A., Shelef, G., 1984. Algal autoflocculation - verification and proposed mechanism. Biotechnol. Bioeng. 26, 142-147.

Taelman, S.E., De Meester, S., Van Dijk, W., da Silva, V., Dewulf, J., 2015. Environmental sustainability analysis of a protein-rich livestock feed ingredient in the Netherlands: microalgae production versus soybean import. Resour. Conserv. Recy. 101, 61-72.

Theodosiou, G., Koroneos, C., Stylos, N., 2014. Environmental impacts of the Greek electricity generation sector. Sustainable Energy Technol. Assess. 5, 19-27.

Vandamme, D., Foubert, I., Fraeye, I., Meesschaert, B., Muylaert, K., 2012a. Flocculation of Chlorella vulgaris induced by high $\mathrm{pH}$ : role of magnesium and calcium and practical implications. Bioresour. Technol. 105, 114-119.

Vandamme, D., Foubert, I., Fraeye, I., Muylaert, K., 2012b. Influence of organic matter generated by Chlorella vulgaris on five different modes of flocculation. Bioresour. Technol. 124, 508-511.

Vandamme, D., Foubert, I., Muylaert, K., 2013. Flocculation as a low-cost method for harvesting microalgae for bulk biomass production. Trends Biotechnol. 31, 233-239.

Vandamme, D., Beuckels, A., Markou, G., Foubert, I., Muylaert, K., 2015. Reversible flocculation of microalgae using magnesium hydroxide. Bioenergy Res. 8, 716-725.

Wan, C., Alam, M.A., Zhao, X.-Q., Zhang, X.-Y., Guo, S.-L., Ho, S.-H., Chang, J.-S., Bai, F.W., 2015. Current progress and future prospect of microalgal biomass harvest using various flocculation technologies. Bioresour. Technol. 184, 251-257.

Wang, Z., Belovich, J.M., 2010. A simple apparatus for measuring cell settling velocity. Biotechnol. Prog. 26, 1361-1366. https://doi.org/10.1002/btpr.432.

Weidema, B.P., Bauer, C., Hischier, R., Mutel, C., Nemecek, T., Reinhard, J., Vadenbo, C.O., Wernet, G., 2013. Overview and Methodology. Data Quality Guideline for the Ecoinvent Database Version 3. The ecoinvent Centre, St. Gallen (Ecoinvent Report 1 (v3).

Wellburn, A.R., 1994. The spectral determination of chlorophylls $a$ and $b$, as well as total carotenoids, using various solvents with spectrophotometers of different resolution. J. Plant Physiol. 144, 307-313. 
Weschler, M.K., Barr, W.J., Harper, W.F., Landis, A.E., 2014. Process energy comparison for the production and harvesting of algal biomass as a biofuel feedstock. Bioresour. Technol. 153, 108-115.

Wu, Z.C., Zhu, Y., Huang, W.Y., Zhang, C.W., Li, T., Zhang, Y.M., Li, A.F., 2012. Evaluation of flocculation induced by $\mathrm{pH}$ increase for harvesting microalgae and reuse of flocculated medium. Bioresour. Technol. 110, 496-502.

Yang, F.F., Xiang, W.Z., Fan, J.W., Wu, H.L., Li, T., Long, L.J., 2016. High pH-induced flocculation of marine Chlorella sp for biofuel production. J. Appl. Phycol. 28, 747-756.

Zhang, X.Z., Wang, L., Sommerfeld, M., Hu, Q., 2016. Harvesting microalgal biomass using magnesium coagulation-dissolved air flotation. Biomass Bioenergy 93, 43-49. Zhu, C.J., Lee, Y.K., 1997. Determination of biomass dry weight of marine microalgae. J. Appl. Phycol. 9, 189-194. 